\title{
Racismo e novo pacto da branquitude em tempos de pandemia: desafios para o Serviço Social
}

\section{Racism and the new pact with whiteness in times of pandemic: challenges for the Social Work}

\author{
Márcia Eurico ${ }^{a}$ \\ (D) https://orcid.org/0000-0003-3450-8593 \\ Renata Gonçalves ${ }^{a}$ \\ (D) https://orcid.org/0000-0002-2470-9095 \\ Tales Fornazier ${ }^{b}$ \\ (D) https://orcid.org/0000-0002-9191-7820
}

\begin{abstract}
Resumo: Neste artigo, examinamos aspectos das desigualdades social, racial e de gênero que a pandemia do novo coronavírus escancarou. O vírus é apresentado como indiferente às classes sociais, mas no Brasil são as periferias mais precarizadas que enterram centenas de milhares de mortos. Face à precarização das políticas sociais, os(as) profissionais do Serviço Social são chamados(as) a lidar com o enfrentamento de velhas expressões da questão social frente ao novo pacto da branquitude que aniquila vidas negras.
\end{abstract}

Palavras-chave: Pandemia. Desigualdades. Racismo. Brancura. Serviço Social.

\begin{abstract}
In this paper we examine aspects of social, racial and gender inequalities that the new coronavirus pandemic has exposed. The virus is presented as indifferent to social classes, but in Brazil it is the most precarious peripheries that bury hundreds of thousands of dead. Faced with the precariousness of social policies, Social Work professionals are called to deal with the confrontation of old expressions of the social question in face of the new pact of whiteness that annihilates black lives.
\end{abstract}

Keywords: Pandemic. Inequalities. Racism. Whiteness. Social Work. 


\section{Pandemia, racismo e intensificação das desigualdades no Brasil}

Eles combinaram de nos matar.

E nós combinamos de não morrer.

Conceição Evaristo

pandemia de coronavírus chega ao Brasil num cenário de profun-
da devastação, em que o aprofundamento da crise econômica e
política se expressa no aumento exacerbado do desemprego, na ampliação do trabalho precarizado e terceirizado na intensificação do genocídio da população negra, em especial dos(as) jovens negros(as) e periféricos(as); no crescimento do feminicídio, sobretudo contra mulheres negras; no massacre das comunidades indígenas e quilombolas; nos explosivos conflitos agrários, na desapropriação de terras e despejos; na destruição do meio ambiente; na proliferação de queimadas etc. Instaurou-se um cenário de barbárie nos diversos âmbitos da vida social, legitimado e impulsionados pelo atual desgoverno de cunho nazifascista de Jair Bolsonaro. Frente ao aniquilamento da vida, o presidente da República do Brasil assumiu uma atitude negacionista. Com relação à pandemia, argumentou tratar-se de uma "gripezinha" e, ironicamente, disse: "e daí?", diante das milhares de mortes que se sucedem a cada dia. No momento em que finalizamos este texto, o Brasil já ultrapassou 150 mil mortes e tem mais de 5 milhões de infectados(as) (entre os casos notificados) pela covid-19, figurando entre os piores índices do mundo em relação às políticas sociais de enfrentamento à pandemia. Deste modo, “o país encontra-se, então, em um quadro econômico terrível [...] e, em meio a uma peculiaridade política, torna-se o 'pior dos mundos' para os que tentam sobreviver ao coronavírus” (Morais, 2020, p. 61).

Bem antes da pandemia, é preciso enfatizar, o Brasil já passava por colossais desafios resultantes da crise do capital, que se agravaram após o golpe contra a presidenta Dilma Rousseff, em 2016. A entrada 
de Michel Temer à frente da Presidência não deixou dúvidas quanto à ruptura com os setores populares.

Antes mesmo de qualquer pronunciamento, um fato chamou a atenção: todos os 24 novos ministros eram homens e brancos. Michel Temer extinguia de uma só vez o Ministério da Cultura e as Secretarias de Direitos Humanos, de Políticas de Promoção da Igualdade Racial e de Políticas para as Mulheres. Tratava-se do primeiro ministério sem mulheres desde 1979, quando findava a gestão ditatorial de Ernesto Geisel (Gonçalves e Abreu, 2018, p. 754; grifos nossos).

Temer como chefe de Estado instalou a ponte para o abismo, o que significou a retirada das parcas políticas sociais duramente conquistadas pela classe trabalhadora nos governos imediatamente anteriores. A eleição de Jair Bolsonaro, em 2018, aprofundou ainda mais esse fosso, com um projeto que não apenas representa a continuidade do golpe, mas escancara o que há de pior na sociedade brasileira, que não hesita em destilar seu ódio de classe (Souza, 2019). Praticamente inertes, assistimos à regressão de inúmeros direitos sociais nas mais variadas áreas: as contrarreformas trabalhista e previdenciária; a Emenda Constitucional no 95, que congelou por vinte anos os gastos da União com despesas primárias, o que significa que não haverá recursos para saúde, habitação, assistência social etc.

E nesse contexto pandêmico, em meio a um discurso de "contenção da crise”, o governo criou a Medida Provisória no 936, ${ }^{1}$ que estabelece a redução de $25 \%$ dos salários para quem ganha até $R \$ 3.135,00$ reais por mês e em até $70 \%$ para quem recebe acima desse valor. Há, ainda, a Medida Provisória no 927, que impôs o congelamento dos salários dos(as) trabalhadores(as) em serviço público nas esferas municipal, estadual e

1 Convertida na Lei no 14.020/2020, que regulamenta a redução proporcional de jornada de trabalho e de salário dos trabalhadores enquanto perdurar o estado de calamidade pública em virtude da covid-19. 
federal, a qual vigorou até 20 de julho de 2020 e mesmo num curto espaço de tempo trouxe prejuízos para a classe trabalhadora. A desqualificação e a redução do papel do Estado são frequentemente invocadas como estratégias da ideologia neoliberal, que defende o "Estado mínimo" para a classe trabalhadora, mas, inversamente, garante o "Estado máximo" para o capital (Netto, 2012).

Portanto, as contrarreformas neoliberais nesse contexto da pandemia só agravaram os processos já existentes de desmonte e de privatização do Sistema Único de Saúde, do Sistema Único de Assistência Social, da Previdência Social etc. As condições de vida dos(as) trabalhadores(as) são ainda mais precarizadas e aviltadas, afetando especialmente aqueles setores mais explorados: populações negras, indígenas, mulheres e LGBTs. Nessa perspectiva, Silvio de Almeida (2020) evidencia que essa dinâmica de crise do capital também é atravessada pelas particularidades étnico-raciais e de gênero, visto que a dominação de classe se realiza articulada com as mais variadas formas de opressões racial e sexual:

O conflito social entre capital e trabalho assalariado não é único conflito existente na sociedade capitalista. Há outros conflitos que se articulam com as relações de dominação e exploração, que não se originam nas relações de classe e tampouco "desapareceriam com ela": são conflitos raciais, sexuais, religiosos, culturais e regionais que remontam a períodos anteriores ao capitalismo, mas que nele tomam uma forma especificamente capitalista. Portanto, entender a dinâmica dos conflitos raciais e sexuais é absolutamente essencial à compreensão do capitalismo, visto que a dominação de classe se realiza nas mais variadas formas de opressão racial e sexual. A relação entre Estado e sociedade não se resume à troca de produção de mercadorias: as relações de opressão e exploração sexuais e raciais são importantes na definição do modo de intervenção do Estado e na organização dos aspectos gerais da sociedade.

O fato de a primeira morte por covid-19 divulgada no país ter sido de uma mulher negra, de 63 anos, trabalhadora doméstica, que contraiu 
o vírus de sua patroa, moradora do Leblon, que havia acabado de chegar contaminada da Itália, não é mera coincidência. Trata-se, como veremos adiante, de relações sociais que expressam as próprias contradições produzidas pelo capitalismo e, ao mesmo tempo, explicitam pungentes particularidades da formação sócio-histórica brasileira, em que as desigualdades de classe estão fundamentalmente entrelaçadas às étnico-raciais e também de gênero, visto que a todo momento a dinâmica do capital reatualiza nossa herança escravocrata, colonialista e heteropatriarcal.

A esse respeito, os dados do IBGE, divulgados em 23 de setembro de 2020, evidenciam o aumento estarrecedor do desemprego no país, cujo número de desempregados(as) subiu 27,6\% em quatro meses de pandemia (Campos, 2020). Em maio, o percentual da população sem emprego no Brasil era de 10,1 milhões, subindo para 12,3 milhões em julho; 12,9 milhões em agosto e, em setembro, esse índice subiu para 13,6 milhões de desempregados(as). A pesquisa também revela as contradições étnico-raciais e de gênero. Entre as mulheres, a taxa de desocupação é 16,2\% maior que entre os homens. A população negra também está entre a maioria de desempregados(as), sendo as mulheres negras as mais atingidas, corroborando com as análises de Lélia Gonzalez (2018), que observa que, no capitalismo, os(as) trabalhadores(as) negros(as) se tornam não somente um exército industrial de reserva, mas uma massa marginal crescente. E, "na medida em que existe uma divisão sexual e racial do trabalho, não é difícil concluir sobre o processo de tríplice discriminação sofrido pela mulher negra (enquanto raça, classe e sexo), assim como sobre seu lugar na força de trabalho" (Gonzalez, 2018, p. 42).

Essa integração dos(as) trabalhadores(as) negros(as), como massa marginal na sociedade de classe, promove formas históricas e multifacetadas de violências, inclusive o genocídio, sobre as populações negras e indígenas, que ainda estão entre as mais acometidas pela covid-19. Uma pesquisa publicada pelo Coletivo Terra, Raça e Classe do MST (2020), no jornal Brasil de Fato, demonstrou que a população negra paulistana tem até $85 \%$ mais chances de morrer por covid-19 do que a população branca. Essa mesma pesquisa também mostrou que apesar de 
negros(as) somarem 43,1\% dos(as) hospitalizados(as), representam mais da metade das mortes. Outro dado revelador: pessoas brancas também são maioria entre as que puderam ser internadas, mas minoria entre as mortas (Sandes, 2020). Em relação à população indígena, os dados do Comitê Nacional de Vida e Memória Indígena (2020) evidenciam que o primeiro caso confirmado de contaminação por covid-19, entre indígenas brasileiros(as), foi de uma jovem de vinte anos do povo Kokama, no Amazonas. O contágio se deu por meio de um médico de São Paulo a serviço da Secretaria Especial de Saúde Indígena (Sesai), que estava infectado com o vírus. Atualmente, os Kokama são os mais afetados em casos de mortes e, num panorama geral entre os(as) indígenas, até o momento cerca de 36 mil foram contaminados(as), 844 morreram e 158 povos foram afetados (Comitê, 2020).

O que salta aos olhos é que o eterno mito da democracia racial, como previu Lélia Gonzalez (2018), cai por terra. Esse mito reproduzido pela ideologia dominante racista sustenta uma contradição hercúlea, pois ao mesmo tempo que tenta escamotear a existência do racismo no Brasil, de forma contrária, o movimento do real nos mostra diuturnamente que:

A discriminação sistemática, processual e histórica cria uma estratificação social que se reverte em inúmeras desvantagens políticas e econômicas aos grupos minoritários, vivenciadas na forma de pobreza, salários mais baixos, menor acesso aos sistemas de saúde e educação, maiores chances de encarceramento e morte (Almeida, 2020).

Ao examinarmos a conjuntura vivenciada no país nesse cenário pandêmico, não podemos descolar da análise os elementos que particularizam a relação entre capital e trabalho. Também não podemos desconsiderar o fato de que a questão social brasileira é mediatizada pela questão étnico-racial e, por isso, não é possível compreendermos a primeira, e as expressões que dela derivam, apartando-nos da análise da segunda. Enquanto a pobreza e todas as contradições do capitalismo se aguçaram durante a pandemia (afetando exponencialmente a população 
negra e indígena), causando uma verdadeira devastação das condições de vida, na outra ponta os ricos ficaram escandalosamente mais ricos, conforme $O$ Globo (2020). Essa situação revela a contradição inerente da sociabilidade capitalista, demonstrando que a questão racial é o constante nó da questão social, pois não podemos perder de vista que "o modo de produção capitalista beneficiou-se enormemente do escravismo e amparou as bases da opressão racial, possibilitando que esta se mantenha e continue a sustentar a reprodução do capital” (Gonçalves, 2018, p. 520).

\section{Novo pacto da branquitude em tempos de pandemia}

Desde a escravidão, a ferida do racismo se mantém aberta, e a pandemia de coronavírus a escancarou. $O$ projeto de nação que se ergueu, em especial a partir do período pós-abolicionista, transformou os(as) trabalhadores(as) negros(as) em escória do proletariado que surgia. 0 capitalismo brasileiro não teve dificuldades em se consolidar sem abrir espaço para uma, mesmo tímida, universalização dos direitos civis, políticos e sociais. Ao contrário, apoiou-se na crescente política eugenista que pretendia "melhorar a raça", sem precisar reconhecer a existência do racismo. A ideologia da democracia racial cuidou de propagar o mito de uma convivência pacífica entre os povos, não reconhecendo que havia no Brasil um "problema negro", como se reconhecia existir nos Estados Unidos com a Lei Jim Crown, e na África do Sul com um regime racial segregacionista. Aqui a sutileza era apresentada como a característica mais contundente do racismo. Sutil para quem?

Vários "homens de sciencia"2 receitaram o antídoto para "curar" a nação da "doença” da negritude. O caso de Batista de Lacerda talvez seja o mais emblemático. Em 1911, como diretor do Museu Nacional do Rio de Janeiro, foi convidado a participar do I Congresso Internacional das

2 A vasta lista de intelectuais do país que interpretaram a realidade brasileira a partir do determinismo racial pode ser encontrada em Schwarcz (1994) e Góes (2018). 
Raças e apresentou a tese "Sobre os mestiços do Brasil", em que, de forma bastante contundente, afirmou que o Brasil mestiço daquele período teria no branqueamento sua perspectiva, saída e solução. Em cem anos o país estaria completamente branco por meio da imigração europeia, capaz de apagar as características negroides que tentassem persistir. A esse respeito, Lacerda (2011, p. 240) enfatiza:

Nós já dissemos que o completo desabrochar das raças superiores, formadas por elementos imigrados de países europeus, deveria, no espaço de um século, dar um aspecto bem diferente do atual à população total do Brasil; quando isso se realizar, os mestiços e o negro terão desaparecido, deixando lugar ao branco; os indígenas terão submergido como aqueles da Austrália, consecutivamente à invasão dos anglo-saxões; os descendentes de portugueses, cruzados com italianos e alemães, formarão uma população de aparência toda europeia, modificada pela ação do clima tropical: população vigorosa, inteligente, amiga do progresso, plena de ardor ao trabalho, que sabe se utilizar de todas as conquistas da civilização para melhorar as condições de sua existência.

Crescia no país um discurso dominante que desqualificava os(as) trabalhadores(as) negros(as) a partir de critérios racistas. Nesse ideário, a nação capitalista brasileira só poderia se transformar numa potência civilizacional se livrando do contingente da população considerado gangrenado e capaz de levar o país à degenerescência. O status de "verdadeira ciência" que as teorias raciais (e racistas) receberam deu a elas as condições para amparar as políticas estatais de organização e edificação de uma classe trabalhadora que seria o símbolo desta nação-potência. O Estado brasileiro não mediu esforços para implementar uma política migratória que correspondesse ao ideal de brancura, sob a justificativa de que era necessária a importação de trabalhadores(as) qualificados(as) para o novo processo de produção.

Tornava-se fundamental melhorar o sangue e a "raça" da nação importando trabalhadores(as) que fossem dotados(as) de determinadas 
características "de uma raça mais nobre, ou melhor, caucásica, branca, europeia e, por essas qualidades, superior" (Moura, 1988, p. 80). A política do embranquecimento passou a ser regra no território nacional. E enquanto trabalhadores(as) brancos(as) oriundos(as) das regiões europeias recebiam incentivos do Estado, a engenhosidade "científica" apresentava os argumentos em defesa da supremacia racial branca e da inferioridade dos(as) trabalhadores(as) negros(as) do Brasil. Essa relação de hierarquia racial, ancorada nos argumentos das teorias racialistas, passava a justificar as desigualdades sociais. O futuro branco e ocidental precisava ser garantido (Schwarcz, 1994).

São grandes os traumas deixados pelas inúmeras políticas de embranquecimento adotadas no país com o respaldo dos ideólogos do darwinismo social. O mesmo discurso da superioridade de um grupo social e da inferioridade de outro impunha definitivamente uma segregação racial. A esse respeito, Lélia Gonzalez escreveu que os diferentes modos de produção das distintas fases de produção econômica no Brasil atualizaram a reinterpretação da teoria do lugar natural de Aristóteles. Segundo a autora, da época colonial aos dias de hoje, existe uma evidente separação quanto ao espaço físico ocupado por dominadores e dominados. O lugar natural do grupo branco dominante são moradias amplas, espaçosas, situadas nos mais belos recantos da cidade ou do campo e devidamente protegidas por diferentes tipos de policiamento: desde os antigos feitores, capitães do mato, capangas etc., até a polícia formalmente constituída (Gonzalez, 1982, p. 15).

$\mathrm{Na}$ outra ponta, a autora identifica o lugar natural do negro: "da senzala às favelas, cortiços, porões, invasões, alagados e conjuntos 'habitacionais' (cujos modelos são guetos dos países desenvolvidos) dos dias de hoje. 0 critério tem sido simetricamente o mesmo: a divisão racial do espaço" (1982, p. 15). Esse lugar social ocupado pela população negra é permeado por estigmas que acabam por impor o desejo da brancura. Num diálogo com Frantz Fanon (2008), Lélia enfatiza que o racismo desempenha um papel ideológico fundamental na internalização da "superioridade" do colonizador pelo colonizado e, visando à exploração e à 
opressão, assume táticas distintas com ao menos duas faces: a do racismo aberto (como a segregação racial estadunidense) e o racismo disfarçado, que Lélia prefere classificar como racismo por denegação (presentes nos países da América Latina). Enquanto nas sociedades de racismo aberto a miscigenação é impensável face à busca pela "pureza" e manutenção da "superioridade" branca, nas sociedades latinas "prevalecem as 'teorias' da miscigenação, da assimilação e da 'democracia racial'” (Gonzalez, 2018, p. 324). Segundo a autora, nessa região constituíram-se sociedades racialmente estratificadas que garantem a superioridade branca do grupo dominante, dispensando o recurso ao racismo aberto. É a ideologia do embranquecimento que mantém negros e povos originários na condição de subalternos.

Veiculada pelos meios de comunicação de massa e pelos aparelhos ideológicos tradicionais, ela reproduz e perpetua a crença de que as classificações e os valores do ocidente branco são os únicos verdadeiros e universais. Uma vez estabelecido, o mito da superioridade branca demonstra sua eficácia pelos feitos de estilhaçamento, de fragmentação da identidade racial que ele produz: o desejo de embranquecer (de "limpar o sangue", como se diz no Brasil) é internalizado com a simultânea negação da própria raça, da própria cultura (Gonzalez, 2018, p. 326).

É nesse sentido que Neusa Santos Souza (1983) enfatiza que nascer com a pele preta ou com traços negroides no Brasil é pertencer a um grupo que foi desenraizado, discriminado racialmente. 0 que, para a psicanalista, não garante por si só uma identidade negra. A estrutura racial da sociedade 0 aprisiona numa imagem alienada (a branca). ${ }^{3}$ Torna-se evidente que a abolição não possibilitou a inserção dos(as) trabalhadores(as)

\footnotetext{
A autora observa que para se livrar dessas correntes é preciso compreender esse processo e "criar uma nova consciência que reassegure o respeito às diferenças e que reafirme uma dignidade alheia a qualquer nível de exploração" (Santos, 1983, p. 77). Assim, dirá a autora, ser negro é um vir a ser. "Ser negro é tornar-se negro" (Idem). Mas este é assunto para outro artigo.
} 
na sociedade de classes. A classe dominante, branca, instaurou mecanismos ideológicos de barragem aos segmentos discriminados e escolheu o branco "como tipo ideal, representativo da superioridade étnica na nossa sociedade" (Moura, 1988, p. 62). Em contrapartida, esta classe impôs ao negro "um tipo negativo, inferior, étnica e culturalmente" (Idem). Nessa perspectiva, Clovis Moura observa que entre os dois polos foi estabelecida "uma escala de valores que vê no branco o modelo superior, no negro o inferior e as demais nuanças de miscigenação mais consideradas integradas ou socialmente condenadas, repelidas, à medida que se aproximam ou se distanciam de um desses polos considerados o positivo e o negativo, o superior e o inferior nessa escala cromática" (Idem). Esse processo levou à fuga simbólica da dor da realidade que marginaliza e discrimina. $O$ resultado foi a busca penosa para identificarem-se com a camada branca dominante.

Luciana Alves (2012), ao examinar o tema, demonstrou que a brancura se tornou um valor a ser perseguido indistintamente. O significado ético, estético, econômico e educacional adquiriu um valor simbólico atrelado à brancura, restando aos grupos sociais a adequação do corpo para corresponder às características impostas por esse ideal, arraigado à concepção de ser branco no Brasil. E se distanciar desse modelo ideal leva à dor da violência que surge já nos primórdios da constituição da identidade negra.

Gislene Aparecida dos Santos (2002) observa que o desprezo, que já ocorria durante a escravidão, aumentou com as políticas de embranquecimento impulsionadas pelo Estado. Enquanto os(as) trabalhadores(as) imigrantes garantiam seu sustento por meio do trabalho, os(as) negros(as) recém-libertos(as) eram inferiorizados(as). E, segundo a autora, somando-se "um mito após o outro, inferioridade, vagabundagem, incompetência, foi esboçando o perfil do homem negro como anticidadão, como marginal" (Santos, 2002, p. 129). Foram imediatamente tratados(as) como um perigo à ordem burguesa (Gonçalves, 2018), passando a compor a franja marginal da sociedade. 
O contexto de pandemia tem exposto justamente essa mentalidade escravista da classe dominante brasileira, explicitando o novo pacto da branquitude no país. Aqui o vírus chegou primeiro às classes mais abastadas, que logo receberam um tratamento nos mais importantes e caros hospitais. Esse novo pacto da branquitute reafirma a escala de valores que vê no branco o modelo superior e no negro o inferior, permitindo que a pandemia de coronavírus se espraie para as periferias mais precarizadas, com os piores indicadores econômicos (faltam moradia adequada, acesso à rede pública de saúde, nutrientes adequados à alimentação e, em geral, suas relações de trabalho são regidas sobretudo pela subcontratação, bicos etc.). Os efeitos têm sido os piores possíveis: são milhões de pessoas infectadas a uma velocidade sem precedentes. Retrato de um Brasil em preto e branco que guarda estreita relação com o desenvolvimento do capitalismo dependente, com relações sociais de produção ancoradas na escravidão e na violência patriarcal.

Nesse contexto de precarização, os(as) profissionais do Serviço Social são chamados(as) a fazer o enfrentamento das velhas expressões da questão social em meio ao novo modo de aniquilamento da vida dos(as) trabalhadores(as), sobretudo os(as) negros(as), que são deixados(as) para morrer nas periferias brasileiras.

\section{Serviço Social, questão social e relações étnico-raciais frente à pandemia}

A questão social na América Latina e no interior da sociedade brasileira precisa ser analisada de maneira particularizada se a pretensão desta investigação é apreender de que modo ainda, na atualidade, a tradição escravocrata impacta no acesso e no tipo de tratamento que as populações negra e indígena recebem no âmbito das políticas sociais brasileiras. As assimetrias raciais não se configuram como uma novidade entre nós. Coube aos brancos europeus o controle dos outros grupos raciais, devido à hierarquia racial por eles imposta. 
Ao apreender as conexões entre assimetrias étnico-raciais, racismo estrutural e institucional e os impactos da covid-19 no Brasil, é possível afirmar que o modo como as políticas sociais estão organizadas concorre para o aumento da vulnerabilidade das populações negra e indígena em todas as esferas da vida cotidiana, seja na preservação da saúde e prevenção das doenças, seja na manutenção do trabalho e do salário, seja no acesso aos territórios com equipamentos públicos que ofereçam cultura e lazer, seja na possibilidade de residir em ambientes salubres e, portanto, menos propícios ao adoecimento físico e psíquico.

Ao Serviço Social, no processo de planejamento, análise e implantação das políticas sociais, tem sido cada vez mais demandada uma análise da realidade social em que os determinantes de raça/cor, gênero e sexualidades precisam ser apreendidos enquanto fatores de proteção ou não, dependendo do grupo étnico-racial ao qual os sujeitos pertencem. Em outros termos, o debate sobre relações étnico-raciais pressupõe apreender as relações sociais racialmente estruturadas, pois "os elementos fundantes que permitem compreender a questão étnico-racial brasileira devem ser apreendidos nos processos determinantes da nossa formação social, aqui sintetizados na colonização, escravidão, constituição do capitalismo e da marcha burguesa (Martins, 2017, p. 277).

$\mathrm{O}$ tratamento discriminatório no acesso aos bens e serviços e às diversas políticas públicas, no período pós-abolição, apenas atualiza a reprodução da pobreza geracional e de mecanismos de permanência das populações negra e indígena nas áreas de maior exclusão econômica, política, social, cultural, religiosa e territorial.

Contudo, inúmeras resistências contra a opressão e a exploração podem ser encontradas na história brasileira. Ao longo do século XX e início do XXI, encontramos inúmeros exemplos a partir do tensionamento de trabalhadores(as) negros(as): a Imprensa Negra; a Frente Negra Brasileira e a luta contra o racismo pela via da educação; o Teatro Experimental do Negro e os embates no âmbito da cultura e da igualdade racial; o surgimento do Movimento Negro Unificado no contexto da ditadura civil/ 
militar; as pesquisas acadêmicas que desmontam o mito da democracia racial brasileira; a mudança de paradigma com a Lei $n^{\circ} 7.437 / 85$, conhecida como Lei Caó, e a tipificação do racismo como crime na Constituição Federal de 1988; o reconhecimento oficial do Estado brasileiro de que o racismo é um problema a ser enfrentado, bem como a importante participação das organizações de mulheres negras (Carneiro, 2002) nos encontros preparatórios para a III Conferência Mundial de Combate ao Racismo, Discriminação Racial, Xenofobia e Intolerância Correlata ocorrida em Durban - África do Sul, em 2001; a Lei no 10.639/2003 e a Lei $n^{\circ} 11.465 / 2008$, que versam sobre as contribuições de africanos e indígenas para a formação do Brasil; e a promulgação do Estatuto da Igualdade Racial — Lei no 12.288/2010 (Eurico, 2018).

Das rebeliões das senzalas aos quilombos, das lutas urbanas às cotas raciais, foram muitas as frentes de lutas do povo negro no Brasil. Passa da hora de essas tantas histórias de resistências emergirem em nossos currículos com vistas à formação de um(a) profissional engajado(a) com um projeto de sociedade que rompa efetivamente com o capitalismo, o racismo e o heteropatriarcado. Ao analisar a produção e a reprodução da vida social no cenário brasileiro para responder às demandas profissionais em tempos de pandemia, o Serviço Social precisa ter como ponto de partida a análise das profundas particularidades da nossa formação social brasileira. Concordamos com Martins (2017), que sem o mergulho nesses elementos que compõem as relações étnico-raciais no Brasil, nossas análises podem não dar conta de apreender a realidade de exploração/dominação vivenciada pela população negra.

Como no Brasil, raça estrutura classe, são as pessoas negras as que, proporcionalmente, mais contribuem para a arrecadação das receitas públicas. Gomor enfatiza, no entanto, que tal conformação do sistema tributário brasileiro não é incidental, é parte da engrenagem que permite a (re)produção de uma ordem social fundada nas desigualdades de classe e raça (Xavier, 2020, p. 10). 
A desproteção social é decorrente de um projeto societário que determina o lugar hierárquico na divisão social, sexual, racial e técnica do trabalho. Cabe enfatizar que a questão étnico-racial ainda precisa ser objeto central das políticas sociais. Se a desigualdade social só pode ser extinta com a distribuição de riquezas e com o fim da propriedade privada, e se o racismo estrutura a sociedade de classes, entendemos que o combate às desigualdades étnico-raciais é tarefa fundamental e urgente para a agenda ético-política do Serviço Social brasileiro.

A superação do racismo e da discriminação racial não se restringe a uma atitude isolada, a uma consciência singular nem a uma única profissão. Uma sociedade livre de todas as formas de exploração e opressão e, portanto, das hierarquias de gênero, raça/etnia, classe e sexualidade só pode construída no campo das lutas sociais.

\section{Referências}

ALMEIDA, S. Capitalismo e crise: o que o racismo tem a ver com isso? Blog da Boitempo, 23 jun. 2020. Disponível em: https://blogdaboitempo.com.br/2020/06/23/capitalismo-ecrise-o-que-o-racismo-tem-a-ver-com-isso/. Acesso em: 11 out. 2020.

ALVES, L. O valor da brancura: considerações sobre um debate pouco explorado no Brasil. Cadernos Cenpec, v. 2, n. 2, p. 29-46, 2012. Disponível em: http://cadernos.cenpec.org.br/ cadernos/index.php/cadernos/article/view/176. Acesso em: 19 out. 2020.

CAMPOS, A. C. Desemprego subiu 27,6\% em quatro meses de pandemia. Agência Brasil, 23 set. 2020. Disponível em: https://agenciabrasil.ebc.com.br/economia/noticia/2020-09/ desemprego-subiu-276-em-quatro-meses-de-pandemia. Acesso em: 14 out. 2020.

CARNEIRO, S. A batalha de Durban. Revista Estudos Feministas, Florianópolis, v. 10, n. 1, p. 209-214, 2002. Disponível em: http://www.scielo.br/scielo.php?script=sci arttext\&pid=S0104-026X2002000100014\&lng=en\&nrm=iso. Acesso em: 8 out. 2020.

COLETIVO Terra, Raça e Classe do MST. O que a atual pandemia revela sobre o 13 de maio de 1888? Brasil de Fato, 13 maio 2020. Disponível em: https://www.brasildefato. com.br/2020/05/13/artigo-o-que-a-atual-pandemia-revela-sobre-o-13-de-maio-de-1888. Acesso em: 14 out. 2020.

COMITÊ Nacional de Vida e Memória Indígena. Panorama geral da Covid-19. Disponível em: https://emergenciaindigena.apiboficial.org/dados_covid19/. Acesso em: 14 out. 2020. 
EURICO, Márcia Campos. A luta contra as explorações/opressões, o debate étnico-racial e o trabalho do assistente social. Serviço Social \& Sociedade, São Paulo, n. 133, p. 515529, 2018.

FANON, F. Pele negra, máscaras brancas. Salvador: Editora da UFBA, 2008.

GÓES, W. L. Racismo e eugenia no pensamento conservador brasileiro: a proposta de povo em Renato Kehl. São Paulo: LiberArs, 2018.

GONÇALVES, R. Quando a questão racial é o nó da questão social. Revista Katálysis, Florianópolis, v. 21, p. 514-522, 2018.

GONÇALVES, R.; ABREU, S. Do plano nacional de políticas para as mulheres ao “machistério" de Temer. Revista de Políticas Públicas, São Luís, v. 22, n. 2, p. 753-771, 2018.

GONZALEZ, L. Primavera para as rosas negras: Lélia Gonzalez em primeira pessoa. São Paulo: Diáspora Africana, 2018.

. O movimento negro na última década. In: GONZALEZ, L.; HASENBALG, C. Lugar de negro. Rio de Janeiro: Marco Zero, 1982.

LACERDA, J. B. Sobre os mestiços do Brasil. I Congresso Universal das Raças, Londres, jul. 1911. História, Ciências, Saúde, Manguinhos, v. 18, n. 1, p. 225-242, 2011.

MARTINS, T. C. S. Oposição entre as lutas anticapitalista e antirracista: realidade ou erro de análise? SER Social, Brasília, v. 19, n. 41, p. 275-295, jul.-dez. 2017. Disponível em: https://periodicos.unb.br/index.php/SER_Social/article/view/14686/12989. Acesso em: 8 out. 2020 .

MORAIS, S. P. A Covid-19 no pior dos mundos: Brasil: 2020. In: LUCENA, C.; PREVITALI, F.; BRETTAS, A. (orgs.). Pandemia Covid-19: a distopia do século XXI. Uberlândia: Navegando Publicações, 2020.

MOURA, C. Sociologia do negro brasileiro. São Paulo: Ática, 1988.

NETTO, J. P. Crise do capital e consequências societárias. Serviço Social \& Sociedade, São Paulo, n. 111, p. 413-429, 2012.

O GLOBO. Ricos ficam ainda mais ricos na pandemia; fortuna das 25 famílias que estão no topo chega a US\$1,4 trilhão. Disponível em: https://oglobo.globo.com/economia/ ricos-ficam-ainda-mais-ricos-na-pandemia-fortuna-das-25-familias-que-estao-no-topochega-us-14-trilhao-24564120. Acesso em: 14 out. 2020.

SANDES, A. Pretos e pardos já são maioria entre as vítimas que morreram por Covid-19. Notícias UOL, 20 maio 2020. Disponível em: https://noticias.uol.com.br/saude/ultimasnoticias/redacao/2020/05/19/negros-e-pardos-ja-sao-maioria-entre-as-vitimas-fataispor-covid-19.htm. Acesso em: 20 maio de 2020. 
SANTOS, Gislene Aparecida. A invenção do ser negro. São Paulo: Educ/Fapesp; Rio de Janeiro: Pallas, 2002.

SCHWARCZ, L. Espetáculo da miscigenação. Estudos Avançados, São Paulo, v. 8, n. 20, p. 137-152, 1994.

SOUZA, J. O que significa Bolsonaro no poder. Brasil de Fato, 8 maio 2019. Disponível em: https://www.brasildefato.com.br/2019/05/08/artigo-or-o-que-significa-bolsonarono-poder-por-jesse-souza. Acesso em: 19 out. 2020.

SOUZA, N. S. Tornar-se negro: as vicissitudes da identidade do negro brasileiro em ascensão social. São Paulo: Graal, 1983.

XAVIER, E. M. (org.). Gênero e raça no orçamento público brasileiro. 1. ed. Brasília: Assecor, 2020 .

\section{Sobre o(as) autor(as)}

Márcia CAmpos Eurico - Assistente social, doutora em Serviço Social e docente do Curso de Serviço Social.

E-mail: marcia.eurico@unifesp.br

Renata GonçAlves - Assistente social, doutora em Ciências Sociais, docente do Curso de Serviço Social e vice-coordenadora do Programa de Pós-Graduação em Serviço Social e Políticas Sociais.

E-mail: renata.goncalves25@unifesp.br

Tales Willyan Fornazier Moreira - Assistente social, doutorando em Serviço Social e docente do Curso de Serviço Social.

E-mail: taleswf@live.com 